\title{
Production and Evaluation of Biogas from Mixed Fruits and Vegetable Wastes Collected from Arba Minch Market
}

\author{
Alemu Mekonnen Tura, Tesfaye Seifu Lemma* \\ Department of Chemistry, Arbaminch University, Arbaminch, Ethiopia \\ Email address: \\ kiyyach@gmail.com (A. M. Tura), dawitsena14@gmail.com (T. S. Lemma) \\ ${ }^{*}$ Corresponding author
}

\section{To cite this article:}

Alemu Mekonnen Tura, Tesfaye Seifu Lemma. Production and Evaluation of Biogas from Mixed Fruits and Vegetable Wastes Collected from Arba Minch Market. American Journal of Applied Chemistry. Vol. 7, No. 6, 2019, pp. 185-190. doi: 10.11648/j.ajac.20190706.16

Received: October 18, 2019; Accepted: December 6, 2019; Published: December 30, 2019

\begin{abstract}
The world is in need of a green, efficient, carbon- neutral energy source to replace fossil fuels. The search for energy alternatives involving locally available and renewable resource is one of the main concerns of governments, scientists, and business people worldwide. Biogas, formed by anaerobic digestion of organic materials makes sustainable, reliable and renewable energy possible. This study involves the construction of a lab scale biogas production plant digester. The production of biogas was carried out by employing the mixed substrates of 13 different fruit and vegetable wastes collected from Arbaminch vegetable market. The materials used as feed were Apple, Mango, Cabbage, Avocado, onion, potato, Tomato, Banana, Lemon, Orange, Carrot, Papaya and cow manure. The total solid, volatile solids, moisture content and ash content of the wastes were examined. The anaerobic digestion of fruit and vegetable wastes mixed with different waste took 35-40 days to produce biogas (for complete digestion). Anaerobic digestion is very sensitive to change in $\mathrm{pH}$ and it is important to maintain $\mathrm{pH}$ of 6.7-7.4 for healthy system. The process resulted in the production of nutrient rich slurry high $\mathrm{C} / \mathrm{N}$ ratio. The presented data on the moisture content, total solid, volatile solid and ash content of the wastes shows that tomato had maximum moisture content of $95.02 \%$ and lemon had the least with a moisture content of $73.4 \%$. The maximum TS were recorded in Avocado (24.47\%). The VS in all wastes used for the study varied from $20 \%$ (carrot) to $46.5 \%$ (Mango) wastes. The characteristics of these wastes were found to be: TS $14.13 \%$ of wet weight, VS $26.71 \%$, TS/VS initial 0.461 and TS/VS final 0.394 which lead to TS/VS lost 0.394 . The carbon and nitrogen composition of these mixed wastes was $53.85 \%$ and $2.205 \%$ respectively. The cumulative biogas production was $105.5 \mathrm{~mL} / 1000 \mathrm{~g}$ of food waste. This was the most effective as it showed maximum percentage removal of organic matter due to efficient working of the digester. Therefore, the application of biogas technology has economic, environmental, health and social benefits. It ultimately contributes towards sustainable development.
\end{abstract}

Keywords: Biogas, Fruit and Vegetable Waste, Anaerobic Digestion, Fermentation

\section{Introduction}

Energy is one of the most important factors to global prosperity. The dependence on fossil fuels as primary energy source has led to global climate change, environmental degradation, and human health problems. In the year 2040, the world predicted will have 9-10 billion people and must be provided with energy and materials [1]. It is estimated that in terms of primary source used, by 2030 , the structure of energy production will be based on: $75-85 \%$ of conventional fuel combustion, $10-20 \%$ of nuclear fission, $3-5 \%$ of water power, approx. $3 \%$ of solar and wind energy [2].

Most of the harmful gases are formed due to incomplete combustion of fossil fuels. As a result of this, there is a growing international quest for an alternative energy source. Biofuel's produced from biomass through fermentation/an anaerobic condition contains $35 \% \mathrm{O}_{2}$ that may result in a more complete combustion of fuel and thus reduces tailpipe emissions [3]. The most common forms of renewable energy are considered the solar, geothermal energy, water, wind and finally the biomass related energy. Some of the most important benefits of using renewable energy are based on the organic composition, lack of fossil driven $\mathrm{CO}_{2}$ emission, does use mainly locally available resources and are solutions for all needs [2], covering best and directly the local community. Through anaerobic digestion, solar energy stored in the algal biomass as a result of the 
photosynthesis reaction could be released as biogas [4]. Biofuel is considered carbon neutral, as the biomass absorbs roughly the same amount of carbon dioxide during growth, as when burnt. There are two major streams of bio-degradable wastes: (i) green waste from parks, gardens etc. and (ii) kitchen/market wastes. The former includes usually 50-60\% water and more wood (lignocelluloses); the latter contains no wood, but up to $80 \%$, by mass, water. Bio-energy from renewable resources is already a viable alternative to fossil fuels; however, to meet the increasing need for bio-energy several raw materials have to be considered. Ligno-cellulose is the most abundant organic material on earth, in diverse quantities, qualities and forms, and is therefore a promising raw material for bio-energy production [5].

Industrial energy demands are rapidly outpacing the available fossil fuel sources, and the need for alternative energy sources is widely recognized [6]. Experts have proposed biogas as one of these new sources. Biogas is a combustible mixture of gases produced from the anaerobic digestion of organic material by a community of microbes. Biogas is naturally produced in large quantities by landfills and waste-water treatment plants. Many farms worldwide have invested in anaerobic digesters to produce small quantities of biogas from organic waste. Because of the wide availability and renewable nature of the organic materials and microbes required for biogas synthesis, biogas is a potentially effective and sustainable energy source. Compared to natural gas, biogas production, processing, and use generate lower greenhouse gas emissions [7].

Biogas is a flammable gas produced when organic materials are fermented under anaerobic condition. Biogas typically consists of $50-60 \%$ methane, $30-45 \%$ carbon dioxide $\left(\mathrm{CO}_{2}\right)$, and small amounts of other compounds like hydrogen sulfide $\left(\mathrm{H}_{2} \mathrm{~S}\right)$ and ammonia $\left(\mathrm{NH}_{3}\right)$, ranging from hundreds to a thousand parts per million [8]. The methane in biogas is a valuable source of energy, while other components are impurities that pose major impediments to the commercial use of biogas [9]. The variable composition is due to the variety of materials that can be used for production of the biogas. $\mathrm{CO}_{2}$ has no energy yield through combustion and greatly reduces the energy yield per volume of biogas due to its high concentration. $\mathrm{H}_{2} \mathrm{~S}$ is toxic and highly corrosive, often damaging machinery used to transport and produce energy from biogas. It also forms a harmful pollutant, sulfur dioxide, upon combustion [10]. Removal of these impurities is necessary to make biogas an effective energy source.

The present study aimed converting non-edible part of fruit and vegetable wastes that was collected from Arba Minch vegetable market. The non-edible parts of these wastes were converted into biogas under biological action.

\section{Methodology}

\subsection{Description of Study Area}

Arbaminch Zuria woreda is Woreda located in Gammo Gofa zone of the around at distance of $275 \mathrm{~km}$ and $505 \mathrm{~km}$ from the regional city, Hawassa and the country capital city, Addis Ababa respectively. Geographically, the Arbaminch woreda is located between $5^{\circ} 42^{\prime}$ and $6^{\circ} 13^{\prime}$ on North latitude and $37^{\circ} 19^{\prime}$ and $37^{\circ} 41^{\prime}$ east longitude.

\subsection{Materials and Methods}

The experiments' for the production of biogas from fruitvegetable wastes (FVW) was carried out in laboratory scale level in Chemistry Department laboratory, College of Natural Sciences, Arba Minch University, Ethiopia. Equipment's used for this experiments were 20 Litre cylindrical plastic anaerobic digester, Plastic bags, Thermometer, Knife, Digital and nondigital driers or oven, Digital $\mathrm{pH}$ meter, Sieves, Mechanical crusher, Balance, Muffle Furnace, Oven, Crucible. The materials or chemicals used for this experiment were Cow dung, Fruit and vegetable wastes (Wastes of Banana, Lemon, Orange, Apple, Mango Papaya, Avagado and vegetable such as Carrot, Cabbage, Tomato, Potato, Lettuce and Onion), $\mathrm{NaOH}, \mathrm{Ca}(\mathrm{OH})_{2}$ and $\mathrm{CaCO}_{3}$, Deionized water, Nitrogen $\left(\mathrm{N}_{2}\right)$ gas.

\subsection{Sample Collection and Preparation for Biogas Production}

The fruit and vegetable wastes (FVW) were collected from the Arba Minch vegetable market. The samples were transported to the laboratory using sterile plastic bags, and stored at $4{ }^{\circ} \mathrm{C}$ until used for the experiments. Cow manure was used in the present study, which is to be collected from the Zuria Woreda small enterprise forms in which the cows were fed with locally available resources. The collection of cow manure was not be more than one day old. The samples were sun dried for twenty days then oven dried at $110^{\circ} \mathrm{C}$ for $10 \mathrm{hrs}$. Before use, the dried samples were grounded by employing wooden pestle and mortar. By using sieving machine in order to obtain powdered samples which is then stored in a separate black polyethylene bags.

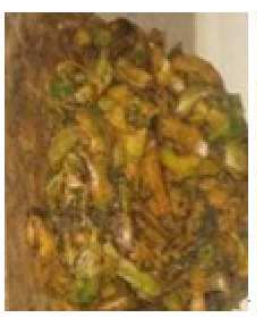

Mango

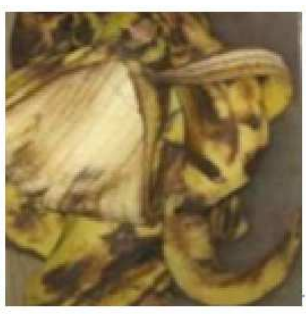

banana peel

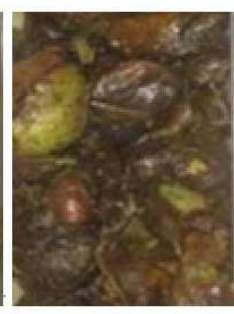

avocado

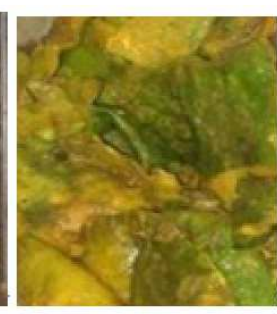

papaya

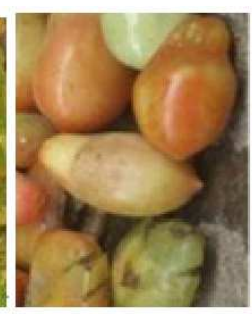

Tomato

Figure 1. FVW collected from Arba Minch Market. 


\subsection{Preparation of Slurry}

From the dried samples, different slurries were prepared and used for the investigations. About $200 \mathrm{~g}$ of each substrate was taken and mixed thoroughly to make as homogeneous mixture; and this mixture was mixed with 1.5 liter of water and transferred into a digester. The biogas produced, from the digester was connected to a separate inverted $1000 \mathrm{~cm}^{3}$ measuring cylinder and volume of biogas produced on digester was recorded.

\subsection{Construction of Anaerobic Digester for Batch System}

The anaerobic biogas generation from fruit and vegetable wastes mixed with cow manure was attempted using a smaller $(10 \mathrm{~L})$ plastic container with dimensions of diameter $24 \mathrm{~cm}$ on each end and a height of $30 \mathrm{~cm}$. The digester, shown in (Figure 2), has two openings. One of these, $5 \mathrm{~cm}$ in diameter, served as inlet for the feed. The second opening, $1.25 \mathrm{~cm}$ in diameter, was connected to a Bunsen burner through a rubber tube, which is to be served as outlet for the gas generation. Both the openings could be made air tight throughout the digestion process.

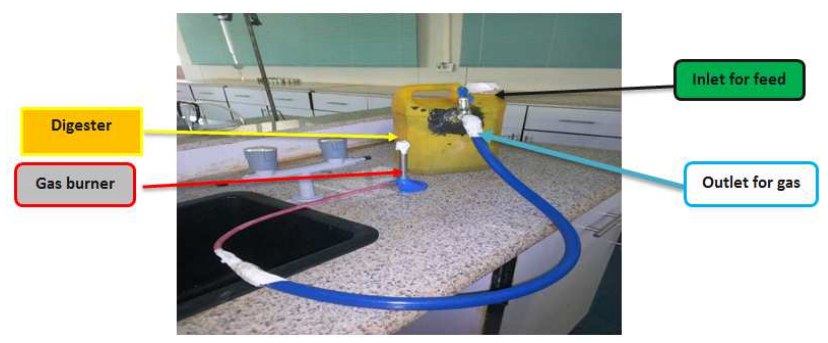

Figure 2. Pilot scale digester of 10 L capacity.

The bio-digester is divided into three main parts- the inlet chamber, the body, and the outlet chamber. An exit $13 \mathrm{~mm}$ diameter hose pipe is provided at the top of the smaller cylindrical portion of the digester for biogas collection and measurement. The digesters used for the experiment was made of plastic with an air tight rubber gasket, which is durable and potable for waste management. Other materials were used for the experiment include graduated plastic bucket, glass flask and beaker for measuring the volume of gas production, gas pressure gauge, hosepipe, thermometer, digital $\mathrm{pH}$ meter. Biogas production was monitored and measured about 35-40 days.

\subsection{Data Collecting and Analysis for FVW}

The physical characteristics (total solids; volatile solids; moisture content and ash content) were analyzed by a standard method for the examination of water and waste water [14]. The temperature and the $\mathrm{pH}$ in each digester were measured at the start. The slurry was sampled at start-up and end of the digestion for the total solids (TS), volatile solids (VS), ash content and moisture content determination.

Physicochemical Analysis

The $\mathrm{pH}$ of digester liquid, influent and effluent, temperature of gas production volume were monitored. In addition to this, TS and VS of the manure after digestion were determined. The TS/VS lost in fermenter and efficiencies of VS conversion to gas was also monitored at the end of the study. The total solid (TS) was determined at $104^{\circ} \mathrm{C}$ to constant weight and VS was measured by the loss on ignition of the dried sample at $550^{\circ} \mathrm{C}$ [15]. These parameters were determined in accordance with APHA.

1. PH Measurement

The $\mathrm{pH}$ of the samples was measured using GENWAY $\mathrm{pH}$ meter.

2. Total solids (TS)

Total solids denote organic as well as inorganic matter in the feedstock [16]. TS was measured according to APHA [14]. About $20 \mathrm{~g}$ of fresh feedstock was weighed $\left(\mathrm{W}_{2}\right)$ in an empty crucible $\left(\mathrm{W}_{1}\right)$ and dried in an oven maintained at $1050^{\circ} \mathrm{C}$ for 24 hour $\left(\mathrm{W}_{3}\right)$. Percent TS is calculated by using equation:

$$
\% T S=\left(\frac{W_{3}-W_{1}}{W_{2}}\right) \times 100
$$

\section{Volatile solids (VS)}

Volatile solids represent organic matter of the feedstock (excluding the inorganic salts, ash). This, too, was measured in accordance with APHA [14]. A $3 \mathrm{~g}$ of oven dried sample was weighed (B) in an empty crucible (A) and heated to $550^{\circ} \mathrm{C}$ for 1 hour in the muffle furnace to constant weight (C). Per cent VS was calculated by using [17]:

$$
\% V S=\frac{C-A}{B} \times 100
$$

\subsection{Indicators of Efficiency}

The performance of the reactor and conversion efficiency of feedstock was estimated by the following indicators:

TS/VS Lost

Initial TS/VS of the feedstock was determined before feeding into the reactor. After destructive sampling, the final TS/VS were determined. The difference between the initial (mass of TS/VS fed) and final TS/VS (residual TS/VS in the digested feedstock) gave the quantity of TS/VS lost. The arithmetic is done by using:

$$
\frac{T S}{V S} \text { lost }=\left[\text { Initial } \frac{T S}{V S}\right]-\left[\text { Final } \frac{T S}{V S}\right]
$$

\subsection{Experimental Procedure}

The FVW were chopped into smaller sizes $(<4 \mathrm{~mm}$ sieve size) to facilitate digestion. Each of the Sample waste was weighted and poured into the mixing tank and then stirred to ensure homogeneity and hermetically sealed. Manual agitation was performed on the digester on a daily basis in order to ensure intimate contact between the microorganisms and the substrate for effective biogas production.

The water tank (beaker) was filled with water to its brim. The gas produced by the substrates inside the anaerobic digester was channeled to the water tank on which two separate holes were drilled at the top, two rubber hoses were inserted in the holes, the first one (1000 $\mathrm{mm}$ in length and $7 \mathrm{~mm}$ in diameter) was 
used to connect the digester while the second $(800 \mathrm{~mm}$ in length and $7 \mathrm{~mm}$ in diameter) was used to connect the water collector. The weight of gas produced was equivalent to the amount of water displaced in the water chamber (Archimedes' principle of floatation). The displaced water was collected in the water collector. The volume of water displaced in the water collector was measured using a measuring cylinder.

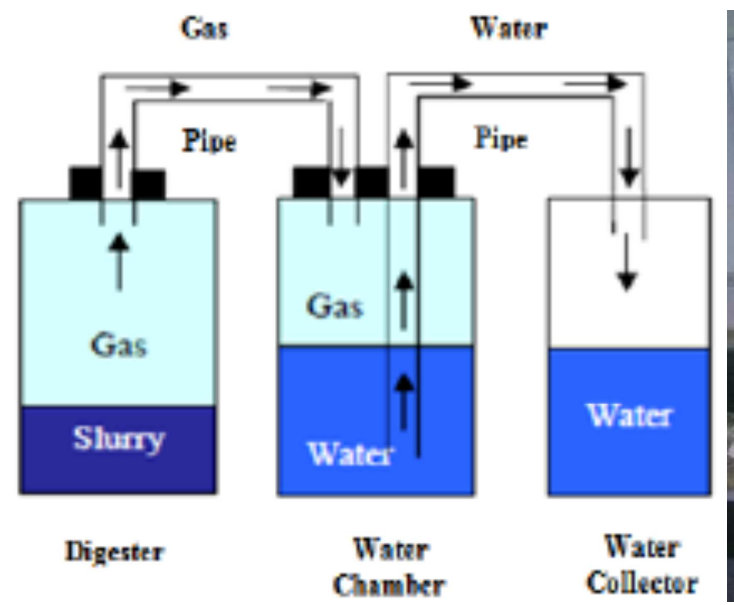

\subsection{Evaluation of Produced Biogas}

\section{Biogas Collection}

Biogas to be produced by anaerobic digestion was measured by water displacement method [18] as shown in Figure 3:

Figure 3. Schematic diagram of water displacement method.

\subsection{Community Benefit}

This current research assures the eco-friendly by use of biomass feedstock and does provide awareness to the society and scientific community. Also, the output of the product is a well-known renewable energy product and it is the one of most concerned area of scientific world. The output of the product biogas can be produced even in house hold with the small accessories, the community can produce the biogas even in their home, and fulfill their needs for cooking by using their kitchen wastes; vegetable and fruit wastes, etc. dispose as domestic waste called garbage. Hence, this research provides the fuel sources for the society/nation, and also to avoid the pollution. Briefly, people/society, researchers, government and non-governmental organizations are the beneficiaries from the outcome of this research.

\section{Result and Discussions}

\subsection{Result}

The characteristics of FVW used for feed is tabulated in the following table. The characterization carried out will be helpful in the production of biogas from FVW.

Table 1. Characterization of FVW wastes used for feed (for each substrate).

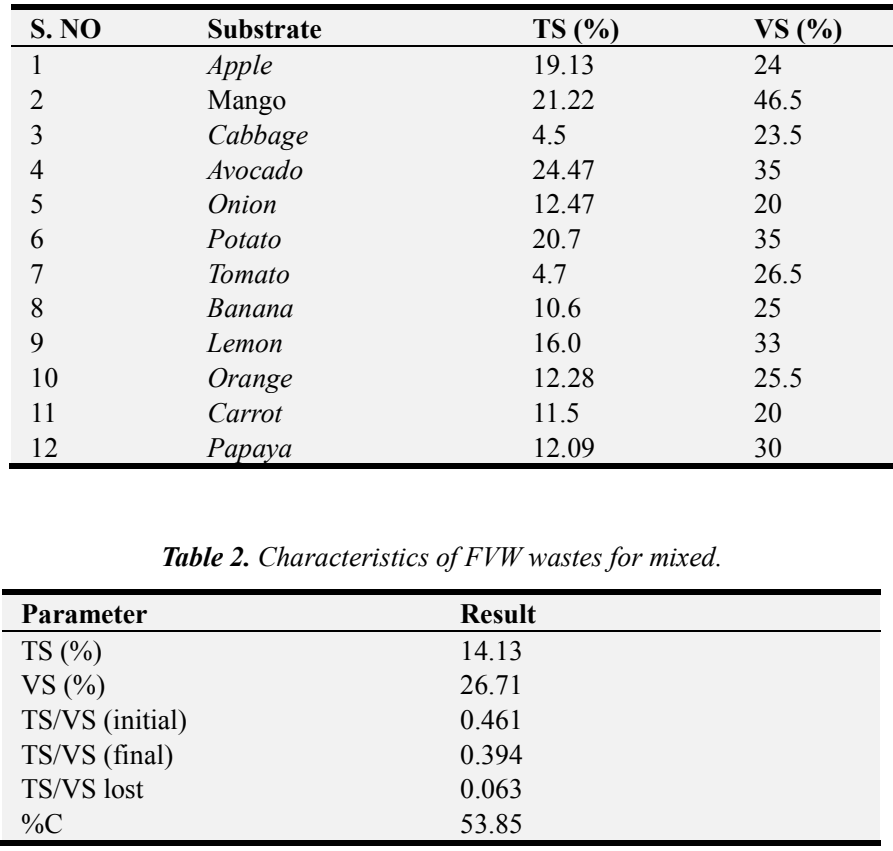

\begin{tabular}{lll} 
Moisture content (\%) & OC (\%) & TS/VS \\
\hline 80.87 & 44.3 & 0.79 \\
78.8 & 31.5 & 0.45 \\
90.5 & 45.4 & 0.19 \\
75.6 & 37.9 & 0.6 \\
87.6 & 46.6 & 0.62 \\
79.2 & 37.9 & 0.5 \\
95.02 & 42.7 & 0.17 \\
89.4 & 43.6 & 0.42 \\
73.45 & 38.8 & 0.49 \\
81.7 & 48.7 & 0.48 \\
86.5 & 46.5 & 0.5 \\
87.9 & 29.19 & 0.4 \\
\hline
\end{tabular}

\begin{tabular}{ll}
\hline Parameter & Result \\
\hline$\% \mathrm{~N}$ & 2.205 \\
$\mathrm{C} / \mathrm{N}$ ratio & 24.47 \\
\hline
\end{tabular}

The presented data on the moisture content, total solid, volatile solid and ash content of the wastes used for the study presents Table 1. From the table it is evident that tomato had maximum moisture content of $95.02 \%$ and lemon had the least with a moisture content of $73.4 \%$. The maximum TS 
were recorded in Avocado (24.47\%). The VS in all wastes used for the study varied from $20 \%$ (carrot) to $46.5 \%$ (Mango) wastes. The results obtained from the present work for individual wastes are comparable with values reported by Mital [9]. Viswanath has reported that banana and tomato contain $15.5 \%$ and $7.5 \%$ TS, respectively [10]. These results are Comparable with values recorded presently. Working on food processing wastes including peels of mango, tomato, lemon, orange and pineapple, Nand has reported that the TS content in them varied from $12.4 \%$ to $23.4 \%$ [11]. The percent of high moisture content in the organic waste facilitates the anaerobic digestion [12].

\subsection{Discussion}

Biogas Production: Biogas generation in the digesters constructed was evident. Combustibility of the biogas generated in the smaller digesters was tested using a Bunsen burner that was connected to the gas outlet through a rubber tube. A sustained flame was expected from combustion of the gas, which was observed. In the smaller digester (plastic digester 10L), biogas gas generation was started after few days of start-up. The total volume of gas so generated is measured by using water displacement method. So, the biogas produced from the mixtures of Fruit and vegetable wastes is $105.5 \mathrm{~mL} / 1000 \mathrm{~g}$. The composition of biogas was not identified due to the lack of the instrument. In 2015 Mohammed Gedifew reported that the cumulative biogas production from $3750 \mathrm{~kg}$ of cow dung was $0.035 \mathrm{~m}^{3} / \mathrm{kg}$ of food waste. This was the most effective as it showed maximum percentage removal of organic matter due to efficient working of the digester [19]. In 2015 Leta Deressa et al., reported that the biogas produced from Fruit and vegetable wastes mixed with cow manure is $0.0371 / \mathrm{g}(37 \mathrm{ml} / \mathrm{g})$. By water displacement method the biogas produced from leftover food waste of students cafeteria mixed with cow manure is $0.042 \mathrm{ml} / \mathrm{g}(42 \mathrm{ml} / \mathrm{g})$ [20]. The present study to those previously reported research it is almost comparable. The TS content and its percentage in VS indicate the fraction of organic matter that can be converted into biogas by the microorganisms, while the $\mathrm{C} / \mathrm{N}$ ratio represents the availability of organic substrate in comparison to the availability of the main nutrient. Macro, micro and trace elements are the fundamental nutrients required by the microorganisms' metabolism. The $\mathrm{pH}$ of mixed wastes in the digester ranged from 6 to 7.2 which are comparable with the optimum range of $\mathrm{pH}$ for production of biogas [13]. This result showed that the microorganisms in the anaerobic digesters were not affected by the $\mathrm{pH}$ of the slurry in the digester. Therefore, no inhibition of biogas production from wastes mixed FVW due to effect of $\mathrm{pH}$. The temperature in the digesters ranged from 26 to $32^{\circ} \mathrm{C}$ which happens to be in the range of mesophilic, $25-45^{\circ} \mathrm{C}$ which is allowed for production of biogas.

\section{Conclusion}

The results of the characterization presented in this study demonstrate that FVWs are an eligible single feedstock for anaerobic digestion. Indeed, they have optimal moisture and Volatile Solid contents and, in accordance with their chemical composition, the maximum expected methane concentration in the biogas produced is $105.5 \mathrm{ml} / 1000 \mathrm{~g}$. The results of the study have revealed that there is a great potential for anaerobic digestion of the organic fraction of food waste in low income societies. The process of biogas production is not merely source of energy, but also used as source of organic fertilizer. As well as, it is a good way to reduce the waste from our society, hence, reduce the radiation of the harmful gases that affects the atmosphere and cause many environmental problems such as global warming. Biogas production process is microbial in nature is affected by temperature, $\mathrm{pH}$, volatile fatty acids, microbial population and ammonia. The control of these factors determines the quality and quantity of biogas produced. Production of biogas from FVW waste is a major step toward harnessing one of the world's most prevalent, yet least utilized renewable energy resource. As the world's population grows and pressure on finite resources increases, we all have a responsibility to adopt the way "reuse, reduce and recycle" when it comes to resources and waste. Through the use of green technologies like anaerobic digestion, can avoid the emission of harmful greenhouse gases and make a positive contribution to environmental targets.

\section{Acknowledgements}

The authors are grateful to Arba Minch University College of natural science department of chemistry for providing equipment and laboratory facilities.

\section{References}

[1] Okkerse, C., \& Bekkum, H. V. (1999). From fossil to green. Green Chem., 1, 107-114.

[2] Popescu, M. C., \& Mastorakis, N. (2010). Aspects regarding the use of renewable energy in EU Countries. WSEAS Transactions on Environment and Development, 6 (4), 265275.

[3] Chandel AK, Kapoor RK, Singh AK, Kuhad RC (2007) "Detoxification of Sugarcane Bagasse Hydrolysate Improves Ethanol Production by Candida Shehatae NCIM 3501", Bio resource Technology, 98, 1947-1950.

[4] Yen, H. W., \& Brune, D. E. (2007). Anaerobic co-digestion of algal sludge and waste paper to produce methane. Bioresource Technology, 98, 130-134.

[5] Petersson, A., \& al, (2007). Potential bioethanol and biogas production using lignocellulosic biomass from winter rye, oilseed rape and faba bean. Biomass and Bioenergy, 31, 812-819.

[6] Demarrias, A. (2010). Use of algae as biofuel sources. Energy Conversion and Management, 5 (1), 2738-2749.

[7] Diaz, I., Perez, S. I., Ferrero, E. M., \& Fez-Polanco, M. (2011) Effect of oxygen dosing point and mixing on the micro aerobic removal of hydrogen sulphide in sludge digesters, Bio resource Technology, 102 (4), 3768-3775. 
[8] Mann, G., Schlegel, M., Schumann, R., \& Sakalauskas, A. (2009), Biogas-conditioning with microalgae, Agronomy Research, 7 (1), 33-38.

[9] Abatzoglou, N., \& Boivin, S. (2008). A review of biogas purification processes. Biofuels, Bioproducts \& Biorefining, 3 (1), 42-71.

[10] Kapdi, S. S., Vijay, V. K., Rajesh, S. K., \& Prasad, R. (2005). Biogas scrubbing, compression and storage: Perspective and prospectus in Indian context. Renewable Energy, 30 (8), 11951202.

[11] Edelmann, W., Joss, A., \& Engeli, H. (1999). Two step anaerobic digestion of organic solid wastes. In J. Mata Alvarez, A. Tilehe, \& J. Cecchi (Ed.), 11 International symposium on anaerobic digestion of solid wastes, (150-153). Barcelona, Spain.

[12] Anunputtikul, W., \& Rodtong, S. (2004). The Joint International Conference on "Sustainable Energy and Environmental (SEE)". (238-243). Hua Hin, Thailand.

[13] Elango M., Pulikesi P., Baskaralingam V., Ramamurthy and Sivanesan S (2007). Production of biogas from municipal solid waste with domestic sewage, Journal of Hazardous Materials. 141 (1), 301.
[14] APHA. Standard Methods for the Examination of Water andWastewater. 20th edition. Washington, D. C, USA. 1998.

[15] Graunke, R. Food and Fuel; Biogas Potential at Broward Dinig Hall, Soil and Water Science, Department University of Florida-IFAS. 2007.

[16] Adams, I, U.; Happiness I, U., (2010) Journal of American Science, 6, 173-178.

[17] Fernandez, B.; Porrier, P.; R. Chamy. (2001), Water. Science Technology, 44, 103-108.

[18] Chua, K. H.; Yip, C. H and Nie, W. L. S. (2008) "A Case Study on the Anaerobic Treatment of Food Waste and Gas Formation".

[19] Mohammed Gedefaw (2015), Biogas production from cow dung and food waste, Global Journal of Pollution and Hazardous Waste Management, 3 (1): 103-108.

[20] Leta Deressa1, Solomon Libs, R. B. Chavan, Daniel Manaye, Anbessa Dabassa (2015), Production of Biogas from Fruit and Vegetable Wastes Mixed with Different Wastes, Environment and Ecology Research, 3 (3): 65-71. 